\title{
DIGA NÃO ÀS SACOLAS PLÁSTICAS: EDUCAÇÃO AMBIENTAL APLICADA NO MUNICÍPIO DE CAMPOS DOS GOYTACAZES
}

\author{
Caroline Gomes Wigand - carolwigand2011@gmail.com \\ Instituto Federal de Educação, Ciência e Tecnologia Fluminense campus Campos \\ Guarus. \\ Isabelle Barcelos Cariman - carimanisabelle@ gmail.com \\ Instituto Federal de Educação, Ciência e Tecnologia Fluminense campus Campos \\ Guarus. \\ Aline Oliveira - aline.oliveira@iff.edu.br \\ Instituto Federal de Educação, Ciência e Tecnologia Fluminense \\ Carine de Oliveira Santos - carine@iff.edu.br \\ Instituto Federal de Educação, Ciência e Tecnologia Fluminense
}




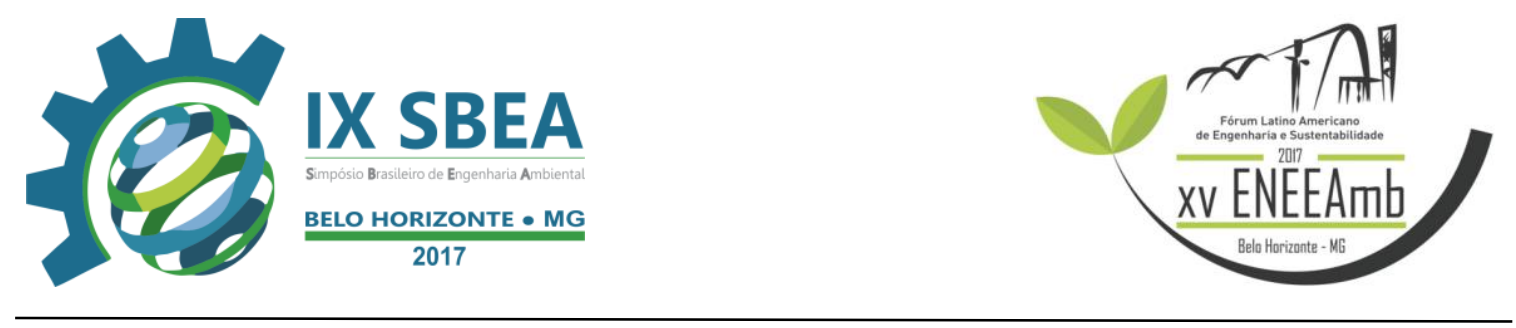

\section{RESUMO}

O presente trabalho é baseado nas informações do projeto de extensão "Diga não às sacolas plásticas" do Instituto Federal de Educação, Ciência e Tecnologia Fluminense (IFFluminense), no qual buscou unir a universidade à sociedade por meio da educação ambiental acerca da temática do uso excessivo das sacolas plásticas. $\mathrm{O}$ projeto visa conscientizar, em especial os frequentadores dos supermercados da região, sobre a importância da redução do uso das "sacolinhas" e o descarte adequado das mesmas, bem como apresentar alternativas para substituí-las. Em busca de resultados efetivos, o projeto realizou uma parceria com a maior rede de supermercados de Campos dos Goytacazes/RJ. Dessa maneira foram realizadas diversas ações, como treinamentos com os caixas e empacotadores, dias de campanhas, panfletagens com uma cartilha informativa sobre o tema, além da divulgação no meio acadêmico. Assim, foi possível identificar que a maioria dos funcionários possuía alguma consciência ambiental a respeito da temática e se mostraram simpatizantes em continuarem a divulgação do projeto. Quanto aos clientes, estes também demonstraram algum conhecimento sobre os impactos negativos que as sacolas plásticas causam ao meio ambiente, mas poucos, no momento do empacotamento de suas compras, se preocuparam em reduzir o número de "sacolinhas".

Palavras-chave: Educação Ambiental, Sacolas Plásticas, Supermercado, Projeto de Extensão.

\section{INTRODUÇÃO/OBJETIVO}

As sacolas plásticas foram inseridas no mercado no final da década de 1970, substituindo as embalagens de papel usadas no comércio. O fato das sacolas serem distribuídas gratuitamente gerou uma revolução na limpeza urbana, pois as sacolas passaram a ser usadas como sacos de lixo pela população, que dispunha o lixo diretamente na rua ou em latões (MINISTÉRIO DO MEIO AMBIENTE, 2011). Nesse contexto, pela busca por praticidade e comodidade as sacolas plásticas proporcionam essa vantagem ao consumidor, o problema é que o uso excessivo e descarte incorreto 


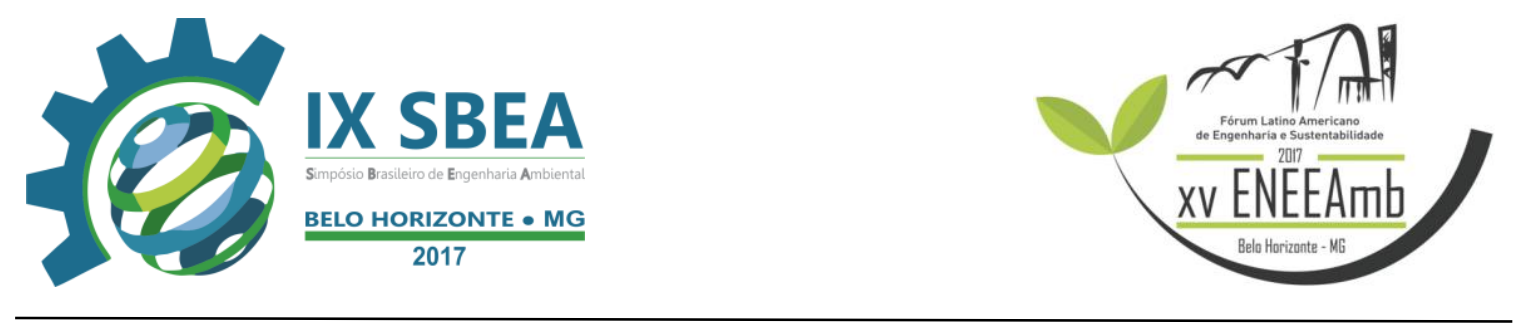

são responsáveis por uma serie de impactos no meio ambiente.

Uma sacola plástica sozinha causa pouco estrago, mas o consumo desenfreado estimulado pela gratuidade tem grande impacto ambiental. No Brasil, estima-se o consumo de 41 milhões de sacolas plásticas por dia, 1,25 bilhão por mês, e 15 bilhões por ano. (MINISTÉRIO DO MEIO AMBIENTE, 2011).

Os plásticos geram impactos ambientais negativos relacionados à vida útil curta e baixo potencial de degradação, podendo levar de 100 a 400 anos no meio ambiente sofrendo ação de raios ultravioletas, umidade e calor até que o mesmo se degrade. As sacolas plásticas provocam ainda efeito cumulativo; poluição visual devido à disposição nas ruas, parques, praças e ambientes turísticos; entupimentos das vias públicas de drenagem; agravamento dos problemas de chuvas fortes como alagamento e engarrafamentos; interferência negativa na alimentação da vida selvagem; alteração do ecossistema e biodiversidade; foco no crescimento de larvas de mosquitos transmissores de doenças como malária e dengue (SANTOS et al., 2012).

Verificou-se também que muitas sacolas, depois de descartadas, acabam em rios, lagos e oceanos, onde são confundidas com alimento e ingeridas por animais, como tartarugas e aves marinhas, causando a morte de mais de 100 mil por ano em todo o mundo. Ainda, para sua confecção são utilizados recursos naturais não renováveis como petróleo e gás natural, além de água e energia, liberando efluentes (líquidos) e gases tóxicos, alguns dos quais acentuam o efeito estufa (MINISTÉRIO DO MEIO AMBIENTE, 2011).

Segundo Bordignon (2011), a busca de alternativas para minimizar os problemas ambientais deve ser feita de forma integrada e coletiva, por isso é necessário o envolvimento de todos os conhecedores dos problemas e das soluções para a proteção do meio ambiente. Nesse contexto, o projeto atua na conscientização ambiental para redução do uso de sacolas plásticas, em especial as distribuídas de forma gratuita nos supermercados da região, divulgando orientações e informações entre os consumidores e sugerindo alternativas para substituir o seu uso.

Para isto, os objetivos do projeto foram delineados da seguinte maneira: coletar o quantitativo mensal de sacolas utilizadas no empacotamento das compras 


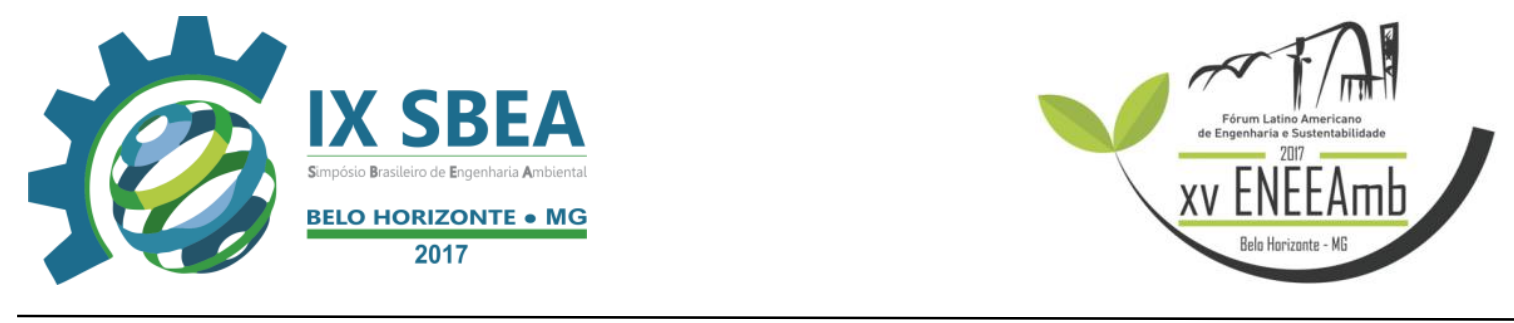

realizadas pelos clientes; identificar a relação do uso das sacolas plásticas e seus impactos ambientais sob a percepção dos clientes; alertar os clientes de supermercado e funcionários a respeito da importância de reduzir o consumo de sacolas plásticas; e divulgar informações, em uma porção da comunidade acadêmica de Campos dos Goytacazes, sobre os problemas ambientais causados pelo uso das sacolas plásticas.

\section{METODOLOGIA}

O estudo se estruturou por meio da pesquisa bibliográfica, coleta de informações em sites oficiais, bem como parcerias e ações de educação ambiental desenvolvidas pelo projeto de extensão "Diga não às sacolas plástica" do IFFluminense, entre 2016 e 2017.

O projeto teve como ação inicial a elaboração de um logo para a identidade e divulgação da ideia "Diga não às sacolas plásticas". Assim foram criados métodos de propagação do conteúdo, como a página no Facebook e uma cartilha informativa, que abordam os seguintes tópicos: "O lixo a as sacolas plásticas", "Problemas ambientais" e "O que devo fazer?" "Como devo mudar?".

As informações inseridas na página do Facebook @ diganaoassacolasplastica e na cartilha foram pesquisadas e selecionadas de artigos científicos e do site da campanha "Saco é um saco" do Ministério do Meio Ambiente. Dessa forma, trazem informações para propiciar mudança de hábitos ao se tratar do uso das sacolas plásticas, nas quais, conforme indica Santos et al. (2012), primeiro é preciso reduzir o consumo, depois associá-lo ao melhor uso para reutiliza-las; além das dicas de gerenciamento doméstico dos resíduos, considerando que o lixo orgânico pode ser utilizado na compostagem e o seco pode ser reciclado, evitando o uso das sacolas para o descarte.

As primeiras ações educativas e disseminadoras do projeto foram realizadas no Colégio Estadual José do Patrocínio (CEJOPA) para os alunos do Ensino Fundamental II, no município de Campos dos Goytacazes, onde houve panfletagem e apresentação de material educativo utilizando recursos de multimídia (slides e vídeos). Além da participação nos eventos Mostra de Extensão: VII IFF-UENF-UFF (2016) e no CONEPE - Ш Congresso de Ensino, Pesquisa e Extensão (2016). 


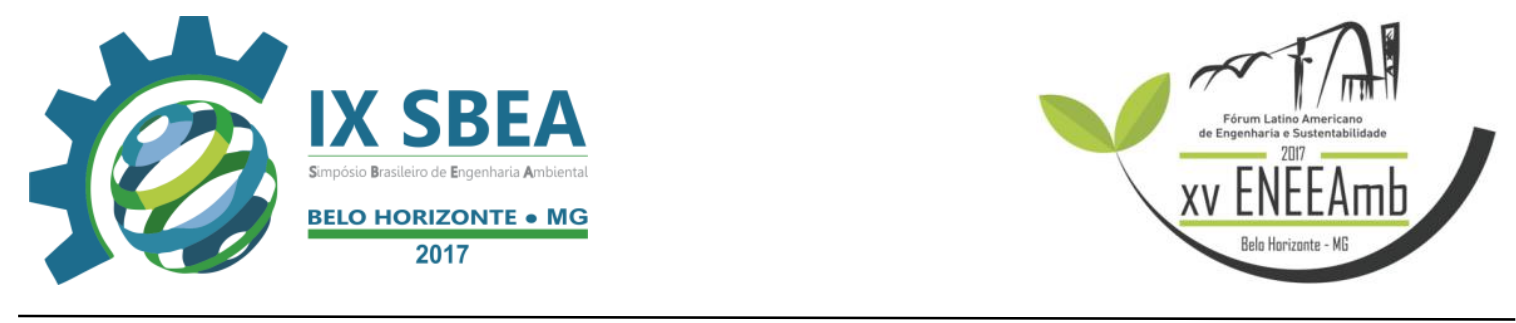

Concomitante a essa divulgação, o projeto realizou uma parceria com a maior rede de supermercados de Campos dos Goytacazes, município do estado do Rio de Janeiro. A partir dessa etapa a rede de supermercados disponibilizou ao projeto a impressão das cartilhas para que fossem utilizadas durante as ações nas unidades do supermercado, além de ecobags para distribuição, como sugestão na substituição das sacolas plásticas.

A primeira atuação em parceria com a rede de supermercados foi realizada em um evento organizado pelo mesmo em uma praia da região. Posteriormente, foram executadas campanhas em duas unidades de supermercado da rede, por meio de panfletagem das cartilhas com os clientes e funcionários e, ainda foram realizadas oficinas de treinamentos com os caixas e empacotadores. A seleção das unidades ocorreu de acordo com a diversidade do público e a localização na região. Nessa etapa, também se obteve o quantitativo mensal de sacolas usadas em uma das unidades da rede.

\section{RESULTADOS E DISCUSSÃO}

Os primeiros resultados alcançados foram o logo, figura 1, e a cartilha informativa (apêndice A), utilizados para disseminação das ações do projeto, além da página do facebook @ diganaoassacolasplastica.

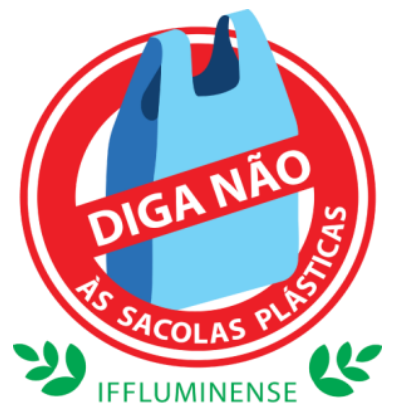

Figura 1 - Logo do projeto.

$\mathrm{Na}$ atividade realizada no Colégio Estadual José do Patrocínio (CEJOPA), escola estadual da região, conforme mostra a figura 2 , verificou-se que os alunos demonstravam certo conhecimento sobre o tema, considerando a ausência de dúvidas ao final da apresentação. Assim, cumpriu-se um objetivo do projeto que é transmitir 


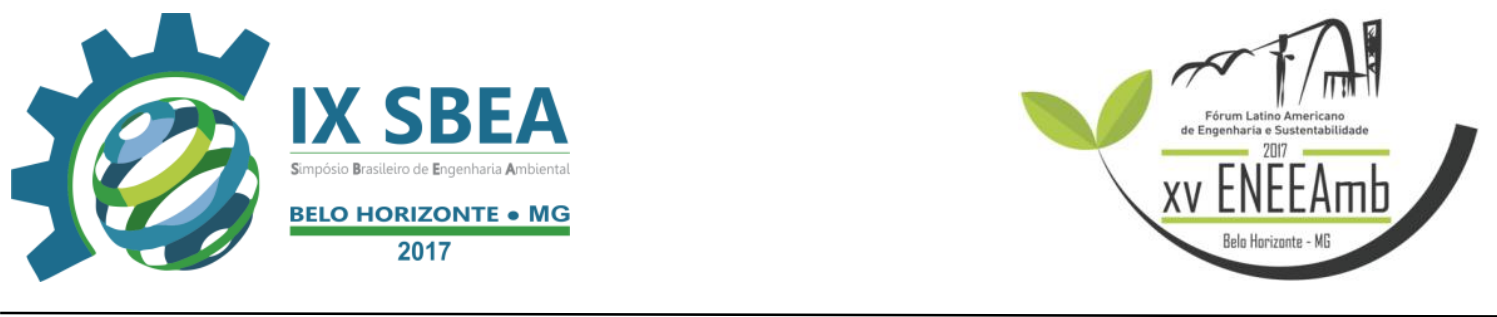

informações a respeito da conscientização e importância de dizer não às sacolas plásticas.

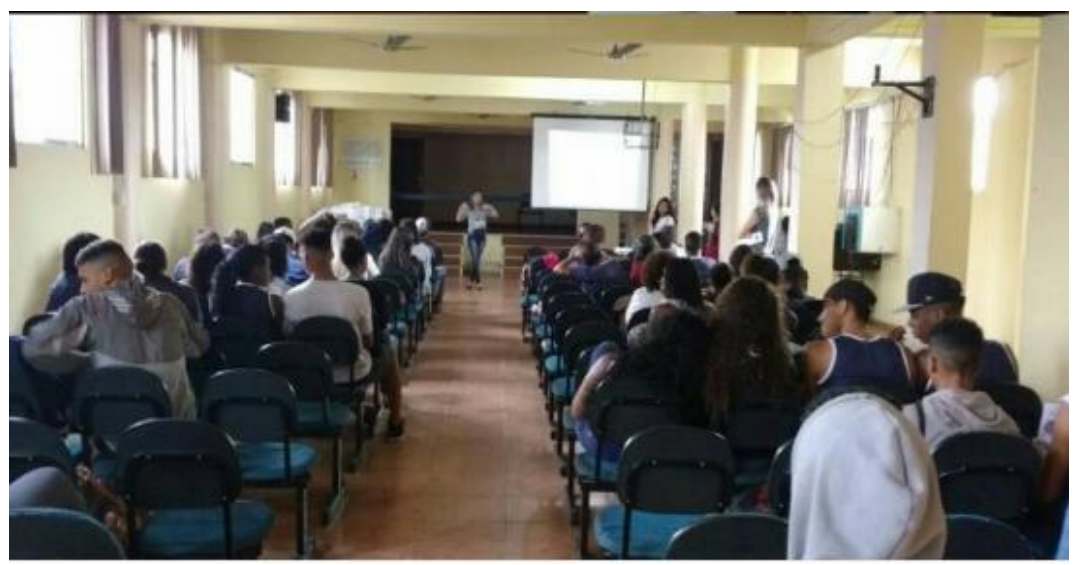

Figura 2- Educação ambiental disponibilizada pelo projeto aos alunos Colégio Estadual José do Patrocínio (CEJOPA), em Campos dos Goytacazes.

O projeto ainda foi divulgado por meio da exposição de banner no III Congresso de Ensino, Pesquisa e Extensão - CONEPE/2016 (Figura 3) e apresentação oral na XIII Semana Nacional de Ciência e Tecnologia/Mostras de Extensão e Pósgraduação IFF-UENF-UFF (Figura 4). Com isto, no decorrer dos eventos acadêmicos, foi possível que o projeto motivasse a educação ambiental no que diz respeito à importância da redução no uso das sacolas plásticas.

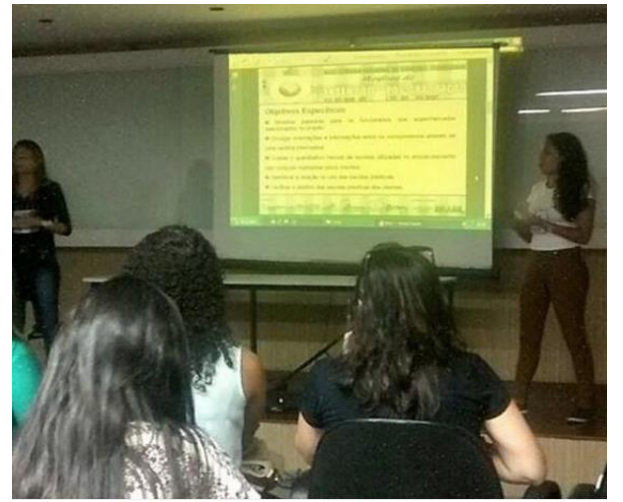

Figura 3- Divulgação do projeto "Diga não às sacolas plásticas” no CONEPE/2016.

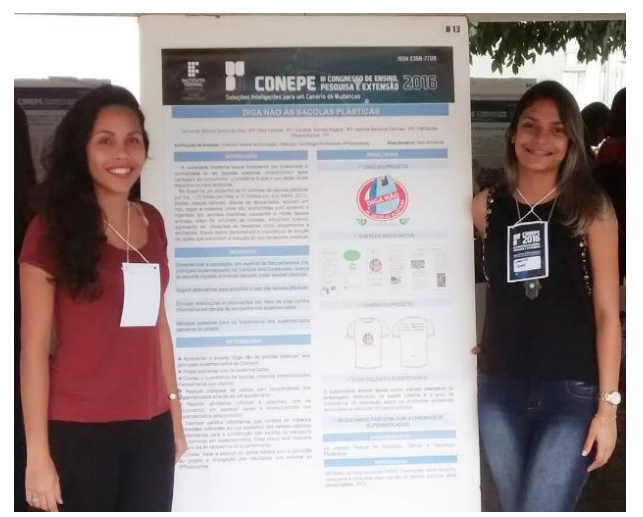

Figura 4 - Divulgação do projeto "Diga não às sacolas plásticas" nas Mostras IFF-UENF-

UFF.

A rede de supermercados que firmou parceria com o projeto é a maior rede de supermercados da região, com várias unidades no município e por essa razão, optou-se por selecionar unidades distantes umas das outras, a fim de atingir públicos distintos.

A primeira ação educativa realizada pelo projeto em conjunto com a rede 


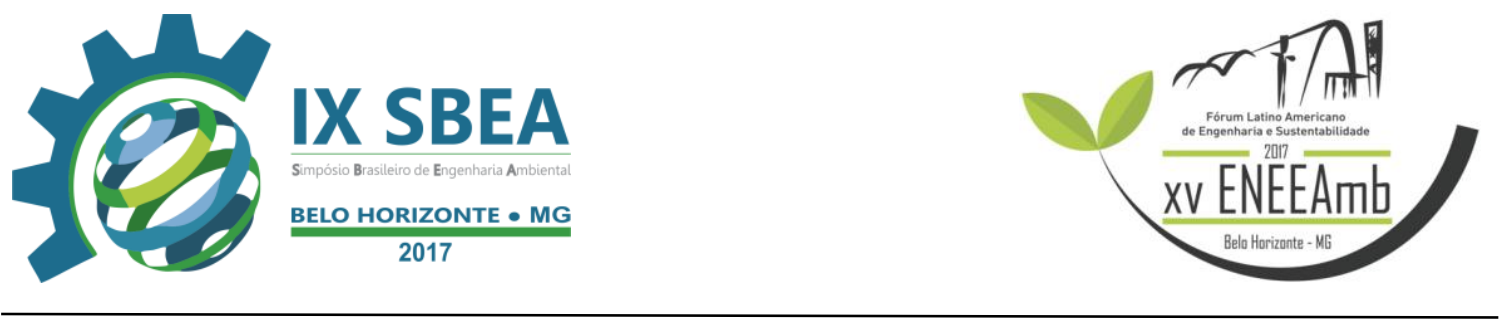

de supermercados foi na região litorânea de Campos dos Goytacazes (Figura 5), na qual se observou grande interesse do público alcançado. Durante a atividade enfatizou-se a importância ambiental e a necessidade de reduzir e descartar de forma correta as sacolas plásticas, sendo facilmente perceptíveis os danos presentes no local da ação, como por exemplo: morte de animais marinhos e lixo presente na areia da praia.

Nessa participação a rede de supermercados forneceu ao projeto 200 (duzentos) ecobags e 1.000 (um mil) panfletos, que foram distribuídos ao longo da ação educativa que teve duração de três semanas, ocorrendo aos sábados.

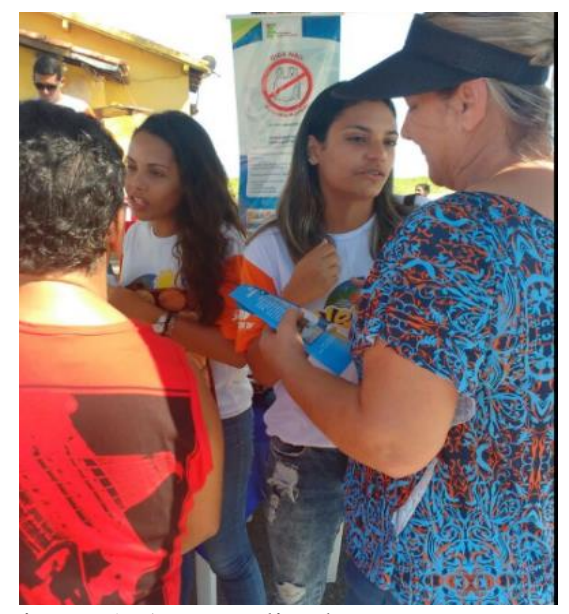

Figura 5- Ação realizada em um evento da rede de supermercados parceira.

Há de se destacar que nas oficinas de treinamento (Figura 6) realizadas com os caixas e empacotadores foi possível verificar que nas duas unidades de supermercado os funcionários possuíam algum conhecimento sobre a temática, incluindo impactos ambientais causados pelas "sacolinhas", as alternativas de substituição e a importância de conscientizar os clientes dos supermercados. Mostraram-se também disponíveis em abordarem com a cartilha informativa os clientes durante o pagamento e empacotamento das compras. Em contrapartida, os mesmos funcionários relataram frequentes solicitações, tais como: o "reforço" de sacolas (duas ou mais), o uso de sacolas mesmo com a utilização de ecobags, a reclamação do valor cobrado pelas sacolas retornáveis disponibilizadas pelo supermercado, dentre outros. Reforçando assim, a necessidade de ações de educação ambiental para redução no uso das sacolas plásticas. 

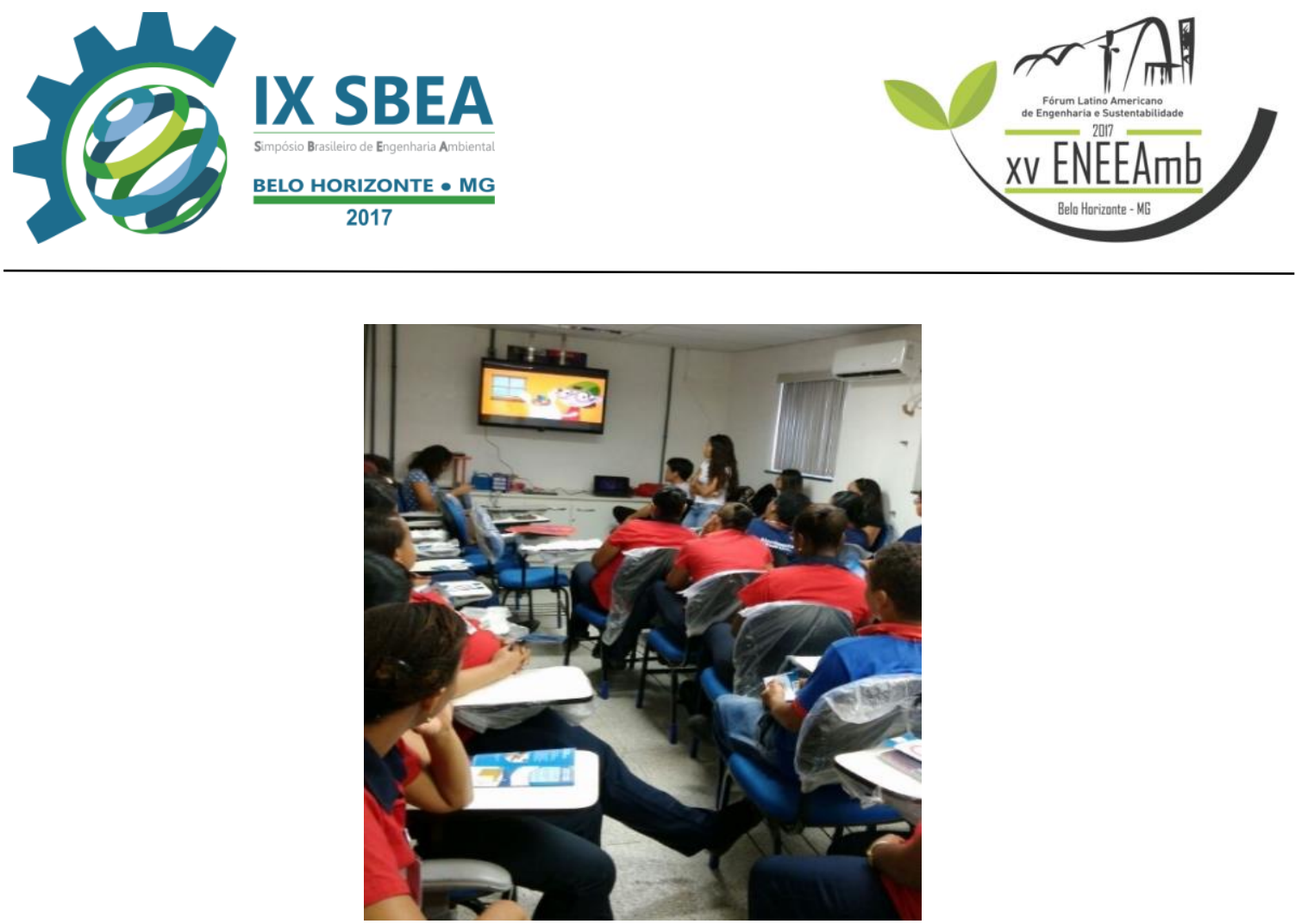

Figura 6 - Treinamento com os funcionários em uma unidade da rede de supermercados parceira.

Quanto aos clientes, a maioria se demonstrou gentil na abordagem e alegava utilizar as sacolas retornáveis, porém havia esquecido de levar no dia. Apesar de demonstrarem interesse durante a entrega da cartilha, muitos a deixaram no carrinho de compras e durante o empacotamento da mercadoria não apresentaram mudanças de atitudes.

Verificou-se, no dia da campanha (Figura 7), que em uma unidade apenas dois clientes fizeram a substituição das "sacolinhas" por outra embalagem retornável.

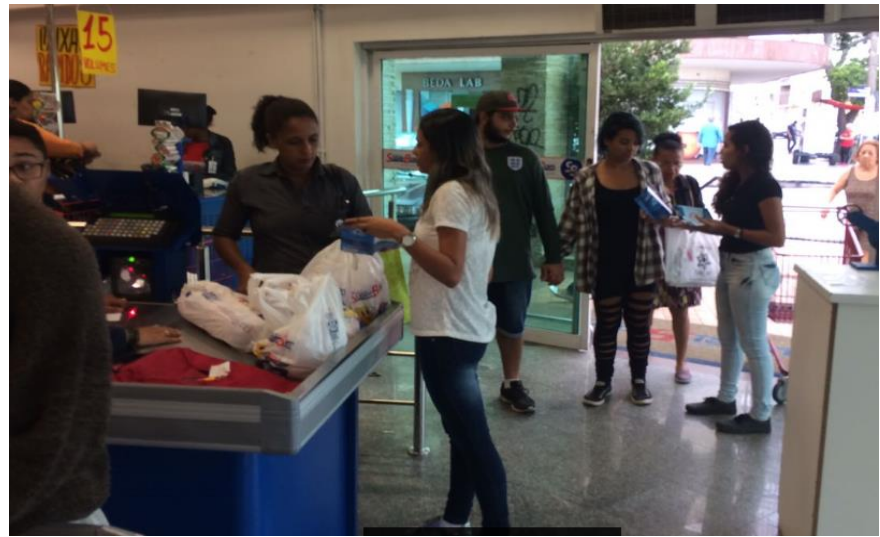

Figura 7 - Panfletagem com a cartilha informativa do projeto em uma unidade da rede de supermercados parceira.

Logo, percebe-se que de modo geral as pessoas têm consciência do impacto

IX Simpósio Brasileiro de Engenharia Ambiental, XV Encontro Nacional de Estudantes de Engenharia Ambiental e III Fórum Latino Americano de Engenharia e Sustentabilidade 


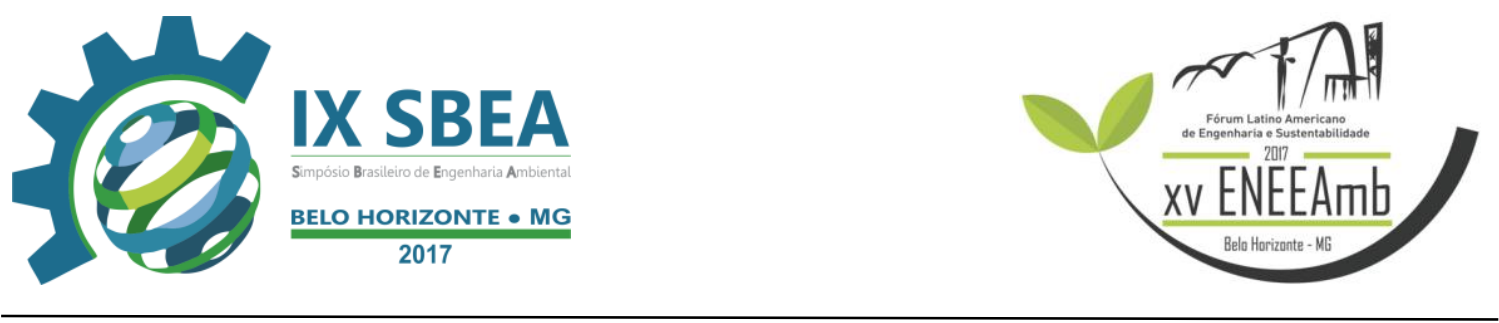

ambiental negativo das sacolas plásticas, por isso se sentem solícitas à abordagem do projeto e muitas vezes envergonhadas, consequentemente a ocorrência de desculpas por não estarem usando sacolas retornáveis. No entanto a praticidade e o comodismo que os sacos plásticos oferecem são elementos que não estimulam a procura por outras formas de levar as compras para casa.

Referente ao quantitativo de sacolas disponibilizadas gratuitamente e usadas pelos clientes nos empacotamentos das compras, uma das unidades registrou o quantitativo de 520.000 sacolas no mês de janeiro e 560.000 no mês de março, em 2017. Com esses dados tem-se o uso médio mensal de 540.000 sacolas em apenas uma das filiais. Estudos teóricas calculam que um consumo anual de 520 sacolas é suficiente para uma família de 4 pessoas, no entanto esse número é superior, no qual chega a 520 sacolas anuais por pessoa (SANTOS et al., 2012). A realidade demonstra a necessidade de medidas para promover a educação ambiental e mudar essa perspectiva.

\section{CONCLUSÕES/RECOMENDAÇÕES}

De acordo com os resultados obtidos durante as ações do projeto, verifica-se que a temática é conhecida, porém devido à comodidade, praticidade e gratuidade adquiridas com o uso das sacolas plásticas, normalmente a população pouco se mobiliza para reduzir ou substituir as mesmas.

Constata-se ainda interesse e preocupação por parte da rede de supermercados e seus funcionários em aderir à campanha de educação ambiental sobre o uso e redução das "sacolinhas", uma vez que estão diretamente ligados à distribuição de sacolas e conscientes do excesso de sacolas distribuídas mensalmente em suas unidades de supermercado. Destaca-se também, que por serem uns dos maiores distribuidores de sacolas plásticas, a imagem do supermercado acaba sendo negativa ao serem encontradas em grande número descartadas de forma incorreta na natureza.

Diante disto é imprescindível a presença de campanhas educativas, tanto com os atores responsáveis pela distribuição das sacolas plásticas, quanto com a população que as utiliza, para que dessa forma o conhecimento adquirido por eles sejam posto em prática. 


\section{REFERÊNCIAS BIBLIOGRÁFICAS}

BORDIGNON, J. Energia e resíduos na Universidade Positivo (UP): promoção do uso sustentável a partir de ações ambientais educativas. Curitiba, 116 p., 2011. Dissertação (Mestrado) - Universidade Positivo.

MINISTÉRIO DO MEIO AMBIENTE. O tamanho do problema. Disponível em: http://www.mma.gov.br/responsabilidade-socioambiental/producao-e-consumosustentavel/saco-e-um-saco/saiba-mais. Acesso em: 24 abr. 2017.

SACO É UM SACO. 2011. Orientações sobre consumo consciente e propostas para redução de sacolas plásticas pelos consumidores. Volume 3. Disponível em: http://www.rc.unesp.br/igce/geografia/downloads/documentos/ana_tereza/cartilha_3_co nsumidores.pdf. Acesso em: 24 abr. 2017.

SANTOS, A. S. F. et al. Sacolas plásticas: destinações sustentáveis e alternativas de substituição. Polímeros, São Carlos, v. 22, n. 3, p. 228-237, 2012. Disponível em: http://www.scielo.br/scielo.php?script=sci_arttext\&pid=S0104-

14282012000300005\&lng=pt\&nrm=iso. Acesso em: 24 abr. 2017. 


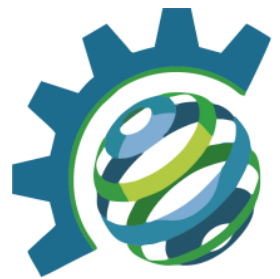

IX SBEA

BELO HORIZONTE • MG

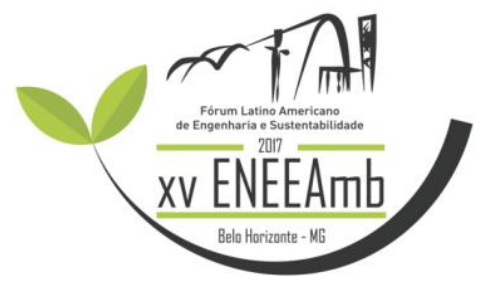

Apêndice A

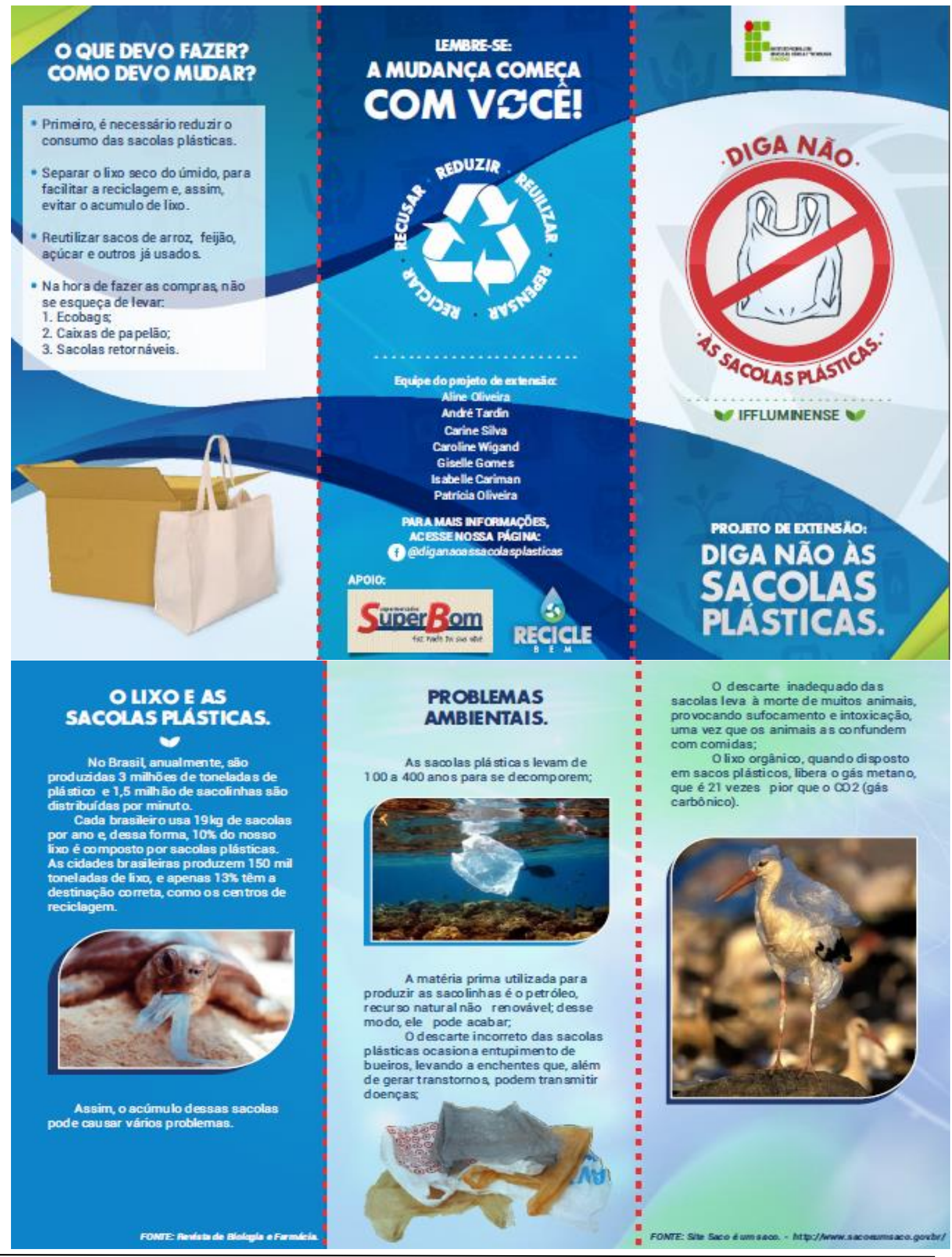

IX Simpósio Brasileiro de Engenharia Ambiental, XV Encontro Nacional de Estudantes de

Engenharia Ambiental e III Fórum Latino Americano de Engenharia e Sustentabilidade 